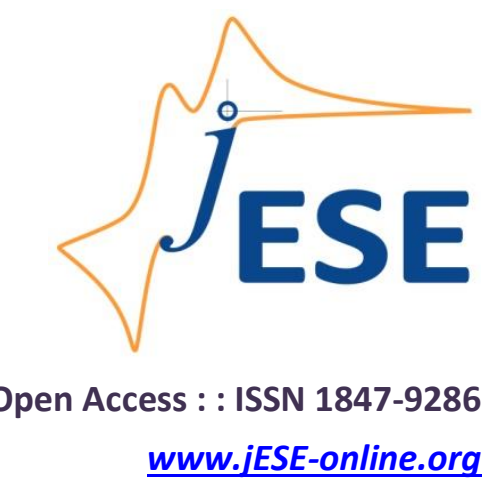

Short communication

\title{
Development of $\mathrm{Zn}-\mathrm{SiC}$ composite coatings: Electrochemical corrosion studies
}

\author{
Mudigere Krishnegowda Punith Kumar, Thimmappa Venkatarangaiah Venkatesha ${ }^{\bowtie}$ \\ and Mudigere Krishnegowda Pavithra \\ Department of Chemistry, Kuvempu University, Shankaraghatta-577451, Shimoga, Karnataka, \\ India
}

${ }^{\bowtie}$ Corresponding Author: E-mail: drtvvenkatesha@yahoo.co.uk; Tel.: +91-9448855079

Received: March 30, 2014; Revised: February 27, 2015; Published: March 15, 2015

\begin{abstract}
The Zn-SiC composite coatings were fabricated by using sulphate plating bath dispersed with 1, 2 and $3 \mathrm{~g} \mathrm{~L}^{-1}$ of $64.28 \mathrm{~nm}$ SiC nanoparticles. Appreciable influence on morphology and microstructure was observed in scanning electron microscopy, X-ray diffraction spectroscopy and texture co-efficient calculations for SiC incorporated zinc coatings. The electrochemical corrosion behavior of zinc and Zn-SiC composite coatings was studied by potentiodynamic polarization and electrochemical impedance analysis. Significant reduction in corrosion current and corrosion rate with increased charge transfer resistance was noticed for composite coatings. The SiC incorporated zinc coatings shown improved micro-hardness property to pure zinc coating. The properties of $\mathrm{Zn}$-SiC composite coatings were compared with that of pure zinc coating.
\end{abstract}

\section{Keywords}

SiC nanoparticles; Electrodeposition; Zn-SiC composite coatings; Corrosion

\section{Introduction}

Zinc has been utilized as a sacrificial layer to protect steel from corrosion. However, the life span of zinc coating is limited in aggressive environment. Consequently, considerable efforts have been made to advance their corrosion resistance property along with other mechanical and physical properties. One of the possible solutions for this is the incorporation of inert particles (nano or micro sized) into a growing $\mathrm{Zn}$ metal matrix during electrodeposition. The second phase particles incorporated metal coatings are called as metal matrix composites (MMCs) and these coatings are renowned for their unique functional properties such as corrosion resistance and wear, hardness, magnetic and semiconducting properties compare to pure metal coating $[1,2]$. 
Also co-deposition of second phase or inert particles with growing metal matrix is environmentally friendly compared to surface modifications using organic chelating agents and hazardous post plating treatment like chrome passivation [3]. The fabrication of MMCs can be achieved by various methods such as electrodeposition, electroless plating, hot dipping, chemical and physical vapor deposition, stir casting and plasma spraying techniques. Among these techniques, electrodeposition has advantages like low cost, room-temperature operation, single step, good reproducibility and ecofriendly. The nanoparticles like $\mathrm{TiO}_{2}$ [4], $\mathrm{ZrO}_{2}$ [5], $\mathrm{CeO}_{2}$ [6] and $\mathrm{SiO}_{2}[1]$ were used to prepare $\mathrm{Zn}$ metal matrix composites and their mechanical and electrochemical behavior have been studied.

However, the silicon carbide $(\mathrm{SiC})$ nanoparticles are well known for their high chemical stability, high temperature resistance and strong heat impact resistance [7]. In literature, substantial reports are accessible on use of $\mathrm{SiC}$ nanoparticles along with nickel matrix to improve mechanical and electrochemical properties of nickel deposits [8-10]. However, not many reports are available on the generation of $\mathrm{Zn}-\mathrm{SiC}$ composite coatings. Swiderska-Sroda et al. [11] used SiC nanoparticles to generate $\mathrm{Zn}$-SiC composite coatings and analyzed their surface appearance and Gabriella Roventi et al. [12] studied the effect of SiC incorporation on the morphology and micro hardness of zinc matrix of $\mathrm{Zn}-\mathrm{SiC}$ composite coatings developed by acidic chloride bath. Nevertheless, the influence of $\mathrm{SiC}$ particles on the corrosion behavior of zinc deposit has not been explored. Hence, the present work has been accomplished to investigate the effect of SiC particles on the corrosion behavior of zinc deposit. The $\mathrm{Zn}$-SiC composite coatings were generated by means of electrodeposition method and also their morphological and electrochemical behavior were studied.

\section{Experimental}

\section{Deposition process}

$\mathrm{Zn}$ and $\mathrm{Zn}-\mathrm{SiC}$ composite coatings were generated on mild steel specimen from zinc plating bath given in the Table 1, which contains separately $0,1,2$ and $3 \mathrm{~g} \mathrm{~L}^{-1}$ of suspended SiC (64.28 nm) nanoparticles. The plating solutions were mechanically agitated for $24 \mathrm{~h}$ by a magnetic stirrer to attain uniform dispersion of $\mathrm{SiC}$ nanoparticles in plating bath. The electrodeposition process was carried out at current density of $0.04 \mathrm{~A} \mathrm{~cm}^{-2}$ [2] for $10 \mathrm{~min}$ with a solution stirring speed of $300 \mathrm{rpm}$.

Table 1. Optimized plating bath composition and operating parameters used for zinc and Zn-SiC composite coating process

\begin{tabular}{|c|c|c|c|c|}
\hline Bath & Constituents & Concentration, $\mathrm{gL}^{-1}$ & Deposit code & Operating parameters \\
\hline \multirow{4}{*}{$\begin{array}{l}\text { Basic } \\
\text { bath } \\
\text { (BB) }\end{array}$} & $\mathrm{ZnSO}_{4}$ & 200 & \multirow{4}{*}{ Z } & \multirow{7}{*}{$\begin{array}{l}\text { Anode: Zinc plate } \\
\text { Cathode: Mild steel plate } \\
\text { Current density: } 0.04 \mathrm{~A} \mathrm{~cm}^{-2} \\
\text { Plating time: } 10 \mathrm{~min} \\
\text { pH } 3.5\end{array}$} \\
\hline & $\mathrm{Na}_{2} \mathrm{SO}_{4}$ & 10 & & \\
\hline & $\mathrm{H}_{3} \mathrm{BO}_{3}$ & 8 & & \\
\hline & CTAB & 0.05 & & \\
\hline $\mathrm{B}_{1}$ & SiC nanoparticles +BB & 1.0 & $\mathrm{ZS}_{1}$ & \\
\hline $\mathrm{B}_{2}$ & SiC nanoparticles +BB & 2.0 & $\mathrm{ZS}_{2}$ & \\
\hline $\mathrm{B}_{3}$ & SiC nanoparticles +BB & 3.0 & $\mathrm{ZS}_{3}$ & \\
\hline
\end{tabular}

\section{Surface characterization}

The surface morphology of the coating was investigated using JOEL JEM 1200 EX II Scanning electron microscopy (SEM) and the $\mathrm{TiO}_{2}$ particle content in the coated film was determined by Energy dispersive X-ray (EDX) analysis coupled with SEM. X-ray diffraction (XRD) analysis of electrodeposits was carried out using Philips TW3710 X-ray diffractometer with $\mathrm{Cu} K \alpha$ radiation $(\lambda=0.1540 \mathrm{~nm})$ working at $30 \mathrm{~mA}$ and $40 \mathrm{kV}$. 


\section{Electrochemical corrosion studies}

The electrochemical corrosion studies were performed in a conventional three electrode glass cell by using $\mathrm{CHI} 660 \mathrm{C}$ electrochemical work station (US make) at $27 \pm 2{ }^{\circ} \mathrm{C}$. A saturated $\mathrm{Ag} / \mathrm{AgCl}$ electrode and a platinum wire served as the reference and counter electrode respectively. The coated specimens were used as working electrode with $1 \mathrm{~cm}^{2}$ exposure area and were immersed in the corrosive media for about $30 \mathrm{~min}$ before polarization and impedance measurements to ascertain the steady state potential or open circuit potential (OCP). For the corrosion studies, $3.5 \% \mathrm{NaCl}$ solution was used as corrosive media.

Tafel curves for coatings were obtained by applying potential between -200 and $+200 \mathrm{mV}$ from their OCP value. Electrochemical Impedance Spectroscopic (EIS) behavior of coatings was measured at their OCP, and the sinusoidal signal amplitude of $5 \mathrm{mV}$ was employed with an alternating current of frequency range from $100 \mathrm{kHz}$ to $10 \mathrm{mHz}$ at 6 points per decade. The measured EIS data were curve fitted and analyzed with the help of commercial ZSimpWin 3.21 software to obtain impedance parameter. Each experiment was repeated thrice to confirm the reproducibility.

\section{Micro-hardness measurements}

The micro-hardness of the $\mathrm{Zn}$ and $\mathrm{Zn}-\mathrm{TiO}_{2}$ composite coatings were measured by Vickers indenter using the instrument "Clemex micro-hardness tester", by forcing a diamond indenter having the geometry as Vickers pyramid, applying the test load $100 \mathrm{~g}$ on the individual specimen. The indentation time was $30 \mathrm{~s}$ on each specimen surface for the individual load.

\section{Results and discussion}

\section{Characterization and surface analysis}

The zinc plating bath solutions (Table 1), each containing $0,1,2$, and $3 \mathrm{~g} \mathrm{~L}^{-1}$ of SiC respectively, were prepared and stirred for $24 \mathrm{~h}$ for the uniform dispersion of nanoparticles. The $\mathrm{Zn}-\mathrm{SiC}$ composite coatings were obtained on mild steel using operating conditions given in Table 1 and the deposits were named in different deposit code and are given in same table. The thickness of the $\mathrm{Zn}$ and $\mathrm{Zn}$-SiC MMCs was calculated by using the Equation 1. The corresponding thickness of the deposits is $14.72,15.24,15.51$ and $15.58 \mu \mathrm{m}$ for $\mathrm{Z}, \mathrm{ZS}_{1}, \mathrm{ZS}_{2}$ and $\mathrm{ZS}_{3}$ coatings, respectively.

$$
T=\frac{m}{A d}
$$

where $m$ is the mass of the deposit, $A$ is the area $\left(\mathrm{cm}^{2}\right)$ and $d$ is the density of the coated metal.

The presence of SiC nanoparticles in the zinc matrix was tested by analyzing the EDX spectra recorded on the $\mathrm{Zn}$-SiC metal matrix composite coatings. The peak corresponds to $\mathrm{Si}$ and $\mathrm{C}$ in the EDX spectra (Figure 1) recorded at different points on composite coating surface confirms the presence of $\mathrm{SiC}$ nanoparticles in zinc matrix. The weight percent of silicon carbide nanoparticles in $\mathrm{Zn}$-SiC MMCs was calculated from the given equation (Equation 2) [12] using the percentage of $\mathrm{Zn}$ and $\mathrm{Si}$ values obtained from EDX analysis.

$$
w_{\mathrm{Sic}}=\frac{w_{\mathrm{Si}}+\frac{w_{\mathrm{Si}}}{P A_{\mathrm{si}}} P A_{\mathrm{c}}}{w_{\mathrm{zn}}+w_{\mathrm{Si}}+\frac{w_{\mathrm{Si}}}{P A_{\mathrm{Si}}} P A_{\mathrm{c}}}
$$

where $P A_{\mathrm{Si}}$ and $P A_{\mathrm{C}}$ are $\mathrm{Si}$ and $\mathrm{C}$ atomic weights respectively and $w_{\mathrm{Si}}$ and $w_{\mathrm{Zn}}$ are mass fractions obtained from EDX data. 


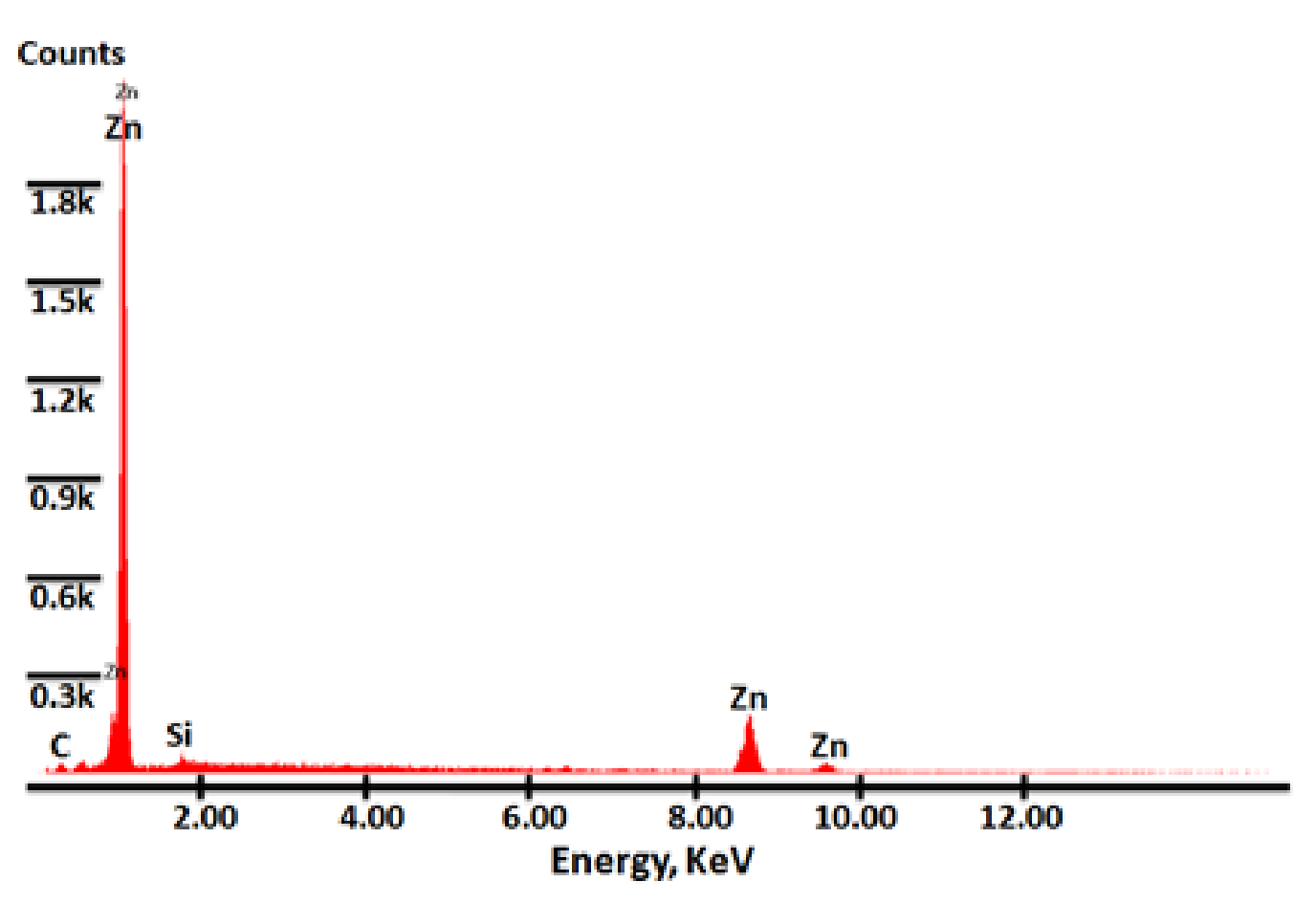

Figure 1. EDX spectra of $\mathrm{Zn}$-SiC composite coating $\mathrm{ZS}_{2}$

Weight percent of $\mathrm{SiC}$ nanoparticles in the deposit is given in Table 2. It can be observed from Table 2 that the amount of SiC nanoparticles in zinc matrix is slightly increased with an increase in the concentration of SiC nanoparticles in the plating bath. About $0.4799 \mathrm{wt} \%$ of SiC particles are embedded in the zinc matrix obtained from the bath solution containing of $2 \mathrm{~g} \mathrm{~L}^{-1}$ nano particles. Figure 2 represents the SEM micrographs of zinc and Zn-SiC MMCs. The randomly distributed, hexagonal zinc platelets without having any local defects were observed in zinc and Zn-SiC deposits but comparatively improved compactness and uniformity was noticed in composite coatings.

Table 2. Weight percent of SiC present in the composite coatings obtained from EDX analysis.

\begin{tabular}{lccc}
\hline coating & $\mathbf{Z S}_{\mathbf{1}}$ & $\mathbf{Z S}_{\mathbf{2}}$ & $\mathbf{Z S}_{\mathbf{3}}$ \\
\hline C K $^{*}$ & 1.93 & 1.98 & 2.01 \\
Si K* & 0.30 & 0.33 & 0.32 \\
Zn K* & 97.77 & 97.69 & 97.67 \\
Total & 100.00 & 100.00 & 100.00 \\
\hline SiC & 0.4361 & 0.4799 & 0.4655 \\
\hline
\end{tabular}

*K shows the peaks generated by $\mathrm{X}$-rays given off as electrons return to the $\mathrm{K}$ electron shell

XRD patterns were obtained for pure zinc and $\mathrm{Zn}-\mathrm{SiC}$ MMCs to know the influence of SiC nanoparticles on the average crystallite size and orientation of zinc crystals, and are provided in Figure 3. The peaks in diffraction pattern correspond to the zinc hexagonal crystal structure (JCPDS card number 04-0831). The peak correspond to SiC nanoparticles were not observed in diffraction patterns, this may be due to the little incorporation ( $\approx 0.45 \%$, from EDX analysis) of SiC nanoparticles in to $\mathrm{Zn}$ matrix. The average grain size of the deposited films was calculated using the Scherrer equation by considering the (101) plane peak broadening (Equation 3) [13]. 


$$
L=\frac{K \lambda}{\beta \cos \theta}
$$

where $L$ - average crystal size, $K$ - Scherer constant, $\lambda$ - wavelength of scattering, $\beta$ - full width half maxima and $\theta$ - scattering angle.
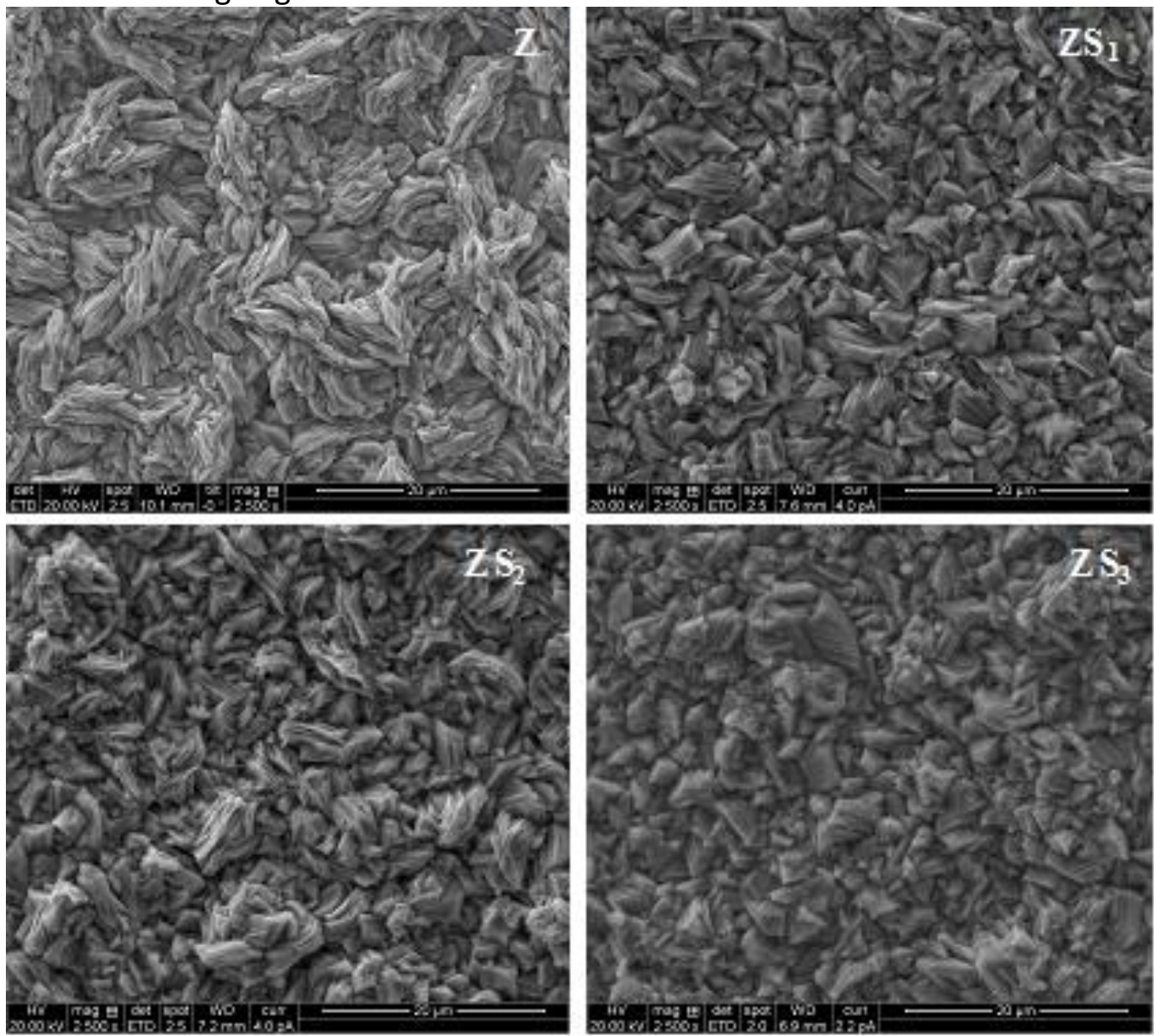

Figure 2. SEM micrographs of as deposited zinc and Zn-SiC composite coatings

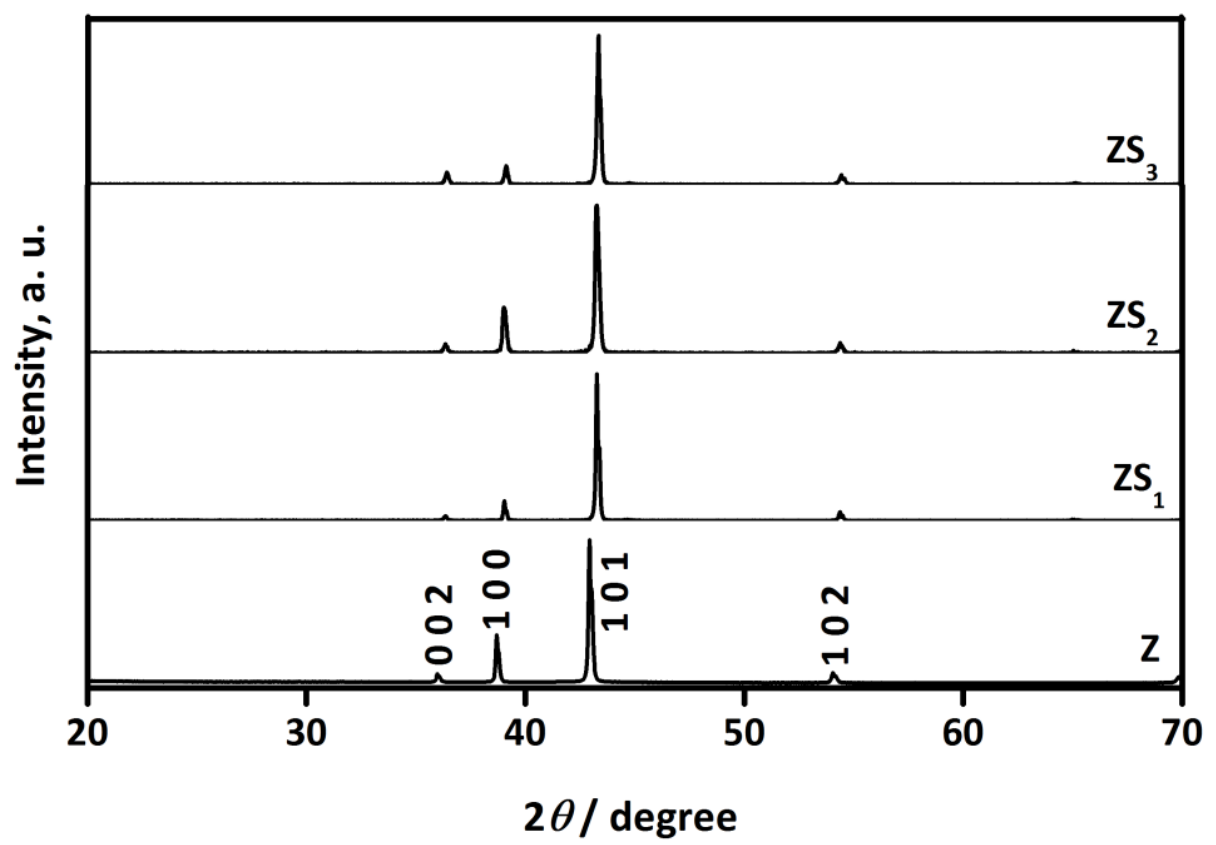

Figure 3. XRD diffractograms obtained from zinc and Zn-SiC composite coatings 
The calculated average crystallite size using Scherrer equation is 89.95, 94.69, 48.80 and $114.76 \mathrm{~nm}$ for $\mathrm{Z}, \mathrm{ZS}_{1}, \mathrm{ZS}_{2}$ and $\mathrm{ZS}_{3}$ deposits, respectively. It can be seen that the inclusion of silicon carbide nanoparticles, significantly influence the grain size of deposit. The change in grain size of the MMCs can be related to the modification of the competition between nucleation and crystals growth in the presence of nanoparticles [4]. The incorporated SiC nanoparticles impede the crystal growth by inhibiting the diffusion of adatoms towards the growing centers and which leads to fresh nucleation [4]. However, in the present work, decrease in average crystal size was observed for $\mathrm{ZS}_{2}$ coating, i.e., for zinc coating, the average crystallite size is $89.95 \mathrm{~nm}$ but it is reduced to $48.80 \mathrm{~nm}$ for $\mathrm{ZS}_{2}$. However in $\mathrm{ZS}_{1}$ and $\mathrm{ZS}_{3}$ coatings, the grain size is not reduced by the $\mathrm{SiC}$ nanoparticles but they impart compactness to the MMCs.

According to literature, the incorporation of second phase particles to growing metal matrix will alter the preferred orientation of the deposit $[4,14]$. Texture co-efficient values are calculated by using Equation 4 [15] for all the XRD profiles and the obtained texture co-efficient values are plotted in Figure 4.

$$
T_{c}(h k l) / \%=\frac{l(h k l)}{\sum l(h k l)} \times \frac{\sum I_{o}(h k l)}{l_{o}(h k l)} \times 100
$$

where, $T_{\mathrm{c}}(\mathrm{hkl})$ is the texture coefficient; $/(\mathrm{hkl})$ is the peak intensity of the zinc electrodeposits; $\Sigma /(\mathrm{hkl})$ is the sum of intensities of the independent peaks and the index ' $\mathrm{o}$ ' refers to the intensities for the standard zinc sample.

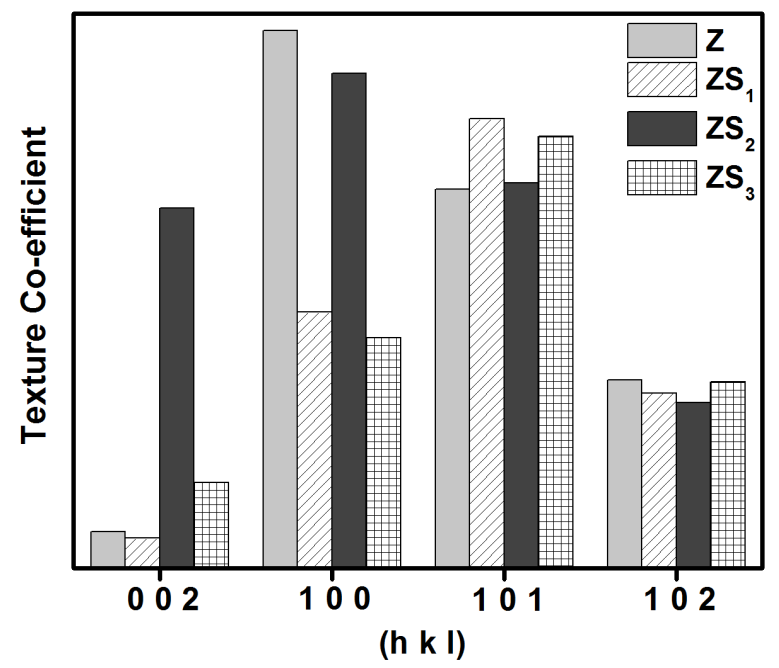

Figure 4. Preferred orientation of crystallites in zinc and Zn-SiC composite coatings.

The preferred orientation plot in Figure 4 reveals that in the zinc deposit, orientation of the zinc crystals is dominated in the (100) plane, however it is changed to (101) plane after the incorporation of $\mathrm{SiC}$ nanoparticles into the zinc matrix.

The change in compactness, average crystallite size and texture co-efficient corresponds to $\mathrm{Zn}$ $\mathrm{SiC}$ MMCs with respect to pure zinc coating reveals the significant influence of $\mathrm{SiC}$ nanoparticles on the morphology and microstructure of the deposits.

\section{Electrochemical corrosion analysis}

Characterization studies confirm that the incorporation of SiC particles to zinc matrix influence the morphology and microstructure of the deposits. And the electrochemical corrosion analysis 
was carried out in order to compare the effect of morphological and microstructural changes on the quality of $\mathrm{Zn}-\mathrm{SiC}$ MMCs with respect to the zinc coating.

\section{Potentiodynamic polarization analysis}

Polarization measurements were carried in order to examine the influence of SiC nanoparticles on the corrosion behavior of the zinc deposits. The potentiodynamic polarization measurement was performed after $30 \mathrm{~min}$ immersion in $3.5 \% \mathrm{NaCl}$ corrosive media. The potentiodynamic polarization curves or Tafel plots were recorded for all the deposits in a potential range of $\pm 200 \mathrm{mV}$ from OCP of the corresponding deposit and are given in Figure 5. The extrapolation on these curves resulted in the determination of corrosion parameters such as corrosion potential $\left(E_{\text {corr }}\right)$, corrosion current $\left(I_{\text {corr }}\right)$, corrosion rate $(\mathrm{CR})$, and anodic and cathodic slopes $\left(\beta_{\mathrm{a}}\right.$ and $\left.\beta_{\mathrm{c}}\right)$ and are tabulated in Table 3.

The decreased corrosion current and little drift in corrosion potential towards positive side for $\mathrm{ZS}_{1}, \mathrm{ZS}_{2}$ and $\mathrm{ZS}_{3}$ reveal that the $\mathrm{Zn}$-SiC composite coatings are more resistive towards corrosive media than pure zinc coating. In particular, $80 \%$ decrease in corrosion rate is noticed for $\mathrm{ZS}_{2}$ deposit. The change in anodic and cathodic Tafel co-efficient values of $\mathrm{Zn}$-SiC composite coatings compare to pure zinc coating indicates that the presence of SiC nanoparticles in the zinc matrix influence the kinetics of both anodic and cathodic electrochemical reactions.

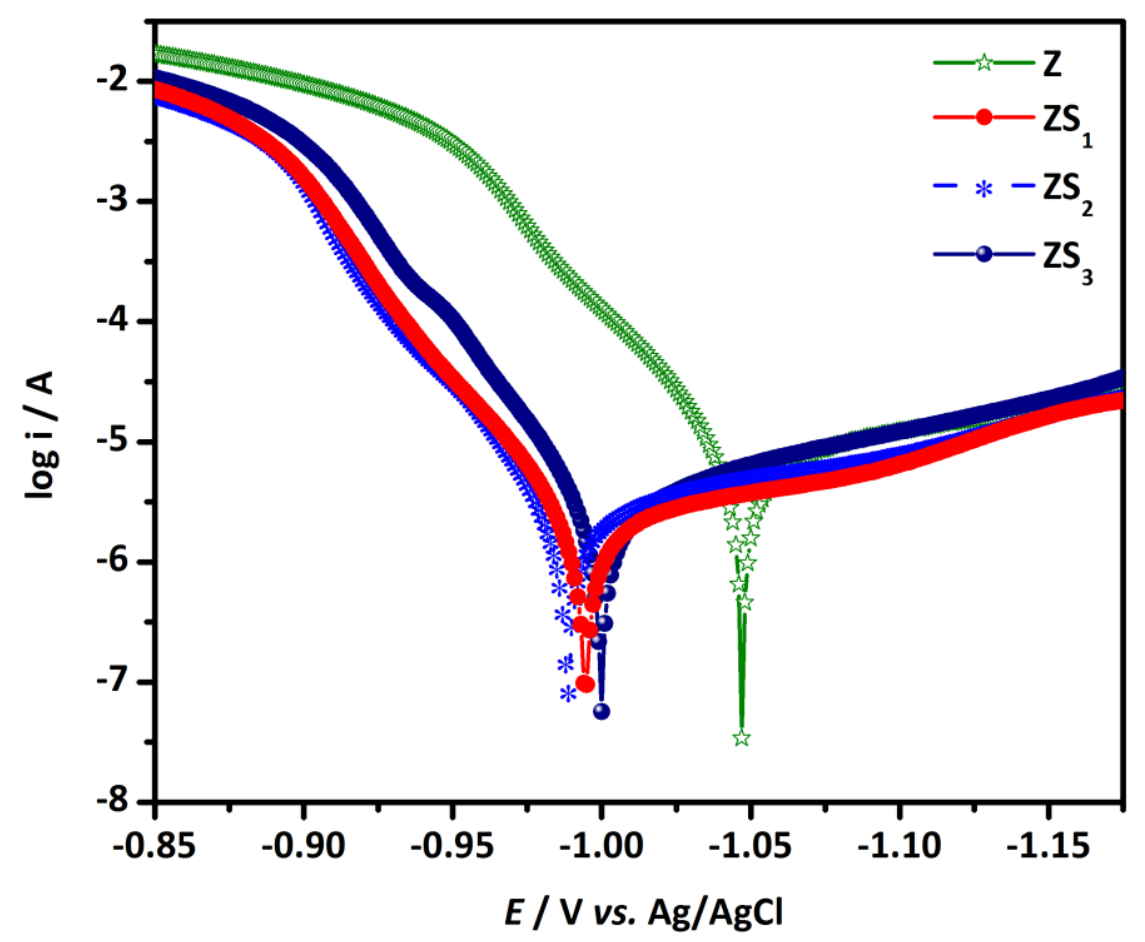

Figure 5. Potentiodynamic polarization curves for zinc and Zn-SiC composite coatings measured with respect to sat. $\mathrm{Ag} / \mathrm{AgCl}$ electrode in $3.5 \% \mathrm{NaCl}$ solution.

Table 3. Electrochemical kinetic parameters of the zinc and Zn-SiC composite coatings derived from Tafel plots.

\begin{tabular}{cccccc}
\hline Specimen & $E_{\text {corr }} / \mathrm{V}$ & $I_{\text {corr }} / \mu \mathrm{A} \mathrm{cm}^{-2}$ & $\beta_{\mathrm{c}} / \mathrm{mV} \mathrm{dec}^{-1}$ & $\beta_{\mathrm{a}} / \mathrm{mV} \mathrm{dec}^{-1}$ & Corrosion rate, $\mathrm{mg} \mathrm{h}^{-1} \mathrm{~cm}^{-2}$ \\
\hline $\mathrm{Z}$ & -1.047 & 8.505 & 280 & 35.72 & 10.06 \\
$\mathrm{ZS}_{1}$ & -0.995 & 2.802 & 248 & 32.80 & 3.314 \\
$\mathrm{ZS}_{2}$ & -0.989 & 2.215 & 182 & 32.92 & 2.620 \\
$\mathrm{ZS}_{3}$ & -1.000 & 3.526 & 192 & 36.69 & 4.170 \\
\hline
\end{tabular}




\section{Electrochemical impedance analysis}

The impedance measurement is the nondestructive and most informative method to assess the corrosion behavior of metal coating. In the present work, the impedance measurement was carried out for all coatings at their open circuit potential in the $100 \mathrm{kHz}$ to $10 \mathrm{mHz}$ frequency range. Initially working electrode was left for $30 \mathrm{~min}$ to attain equilibrium potential in $3.5 \% \mathrm{NaCl}$ solution before EIS measurement.

The measured electrochemical impedance (EIS) data are presented as Nyquist and typical Bode plots in Figure 6(a) and Figure 6(b) respectively. Two capacitive loops or two time constants corresponds to corrosion process are observed in the Nyquist and Bode plots. The shape of the spectra is influenced by the electrochemical process at the surface and/or by the geometric factors of the electrode [16]. Hence to obtain electrochemical parameters, the experimentally determined EIS data were fitted with a suitable electrical equivalent circuit (EEC) given in Figure 7, with the help of the ZSimpWin 3.21 software. To get appreciable fitting results the employed high frequency capacitance element $(C)$ in EEC was replaced by constant phase element (CPE). The impedance of CPE is defined as

$$
Z(i \omega)=(Q)^{-1}(i \omega)^{-n}
$$

where $Q$ is the CPE constant, $i$ is the imaginary unit, $\omega$ is the angular frequency $(\omega=2 \pi f, f$ is the frequency) and ' $n$ ' is the CPE exponent (where ' $Q$ ' and ' $n$ ' are frequency independent parameters). The value of ' $n$ ' lies between -1 and 1 (i.e., $-1 \leq \mathrm{n} \leq 1$ ), for ideal capacitor $n=1$, for ideal inductor $n=-1$, if $n=0$ the CPE is ideal resistor $[17,18]$.
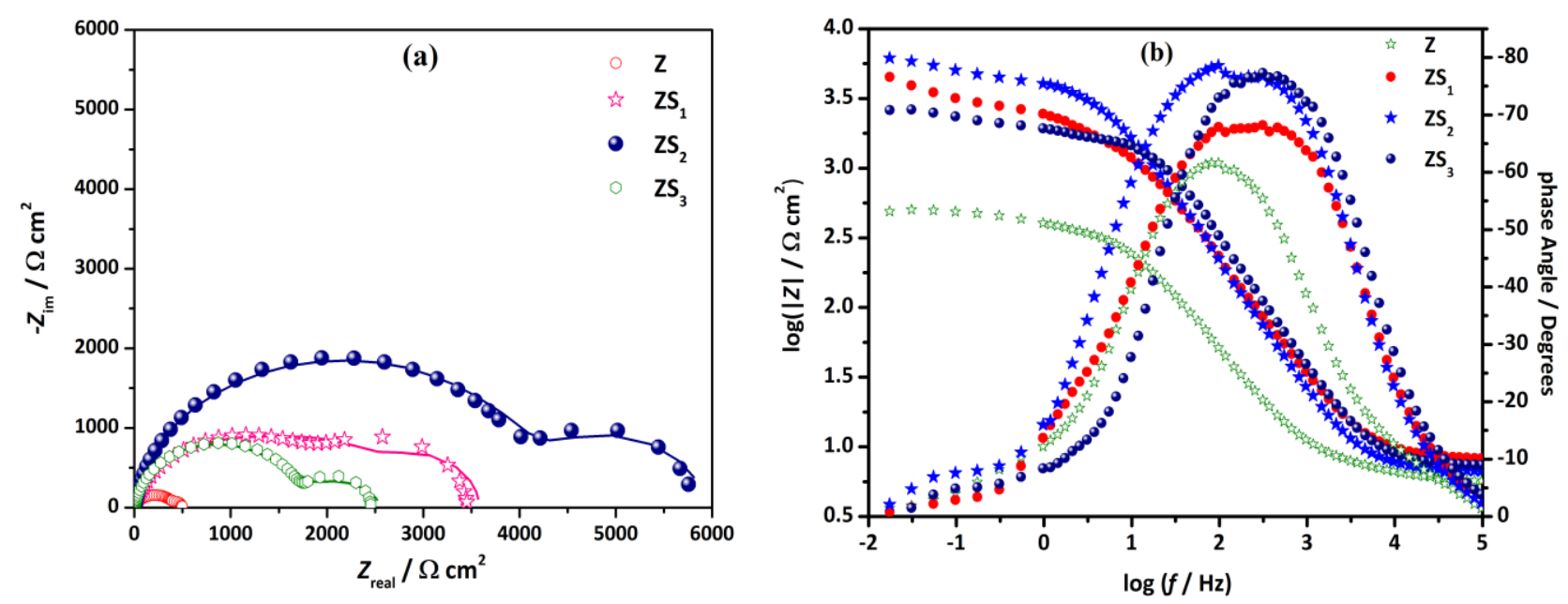

Figure 6. Impedance (a) Nyquist and (b) Bode plots for zinc and Zn-SiC composite coatings measured with respect to Sat. $\mathrm{Ag} / \mathrm{AgCl}$ electrode in $3.5 \% \mathrm{NaCl}$ solution.

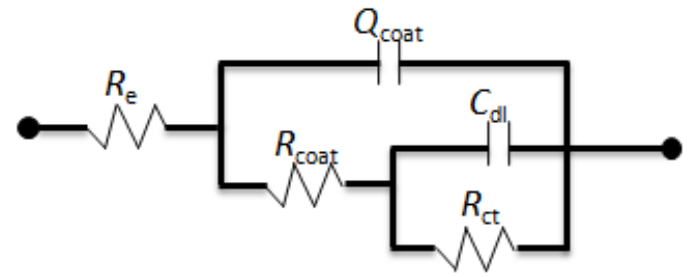

Figure 7. Electrical Equivalent Circuit used to simulate the recorded Impedance Nyquist plots.

The contribution of each element in the used EEC is as follows [19].

$R_{\mathrm{e}}$ is the electrolyte resistance that appeared between the reference electrode and the surface working electrode. The high frequency contribution $\left(Q_{\text {coat }}-R_{\text {coat }}\right)$ is ascribed to the dielectric 
character $Q_{\text {coat }}$ of the coating that is reinforced by ionic conduction through its pores $R_{\text {coat }}$. The low frequency contribution is attributed to the double layer capacitance $\left(C_{\text {dll }}\right)$ at the electrolyte/coated surface interface at the bottom of the pores coupled with the charge transfer resistance $\left(R_{\mathrm{ct}}\right)$.

The obtained corrosion parameters are tabulated in Table 4. The polarization resistance was calculated by adding $R_{\text {coat }}$ and $R_{\text {ct }}$ of the corresponding deposits. The constant phase element is considered as capacitor because the value of CPE exponent ' $n \approx 1$ '. The extent of anticorrosive nature of the deposit can be analyzed by the resistance offered by the deposit, considering both coating resistance and charge transfer resistance. The polarization resistance exhibited by the pure zinc coating $Z$ is $494.8 \Omega \mathrm{cm}^{2}$. The incorporation of SiC particles significantly influenced on the

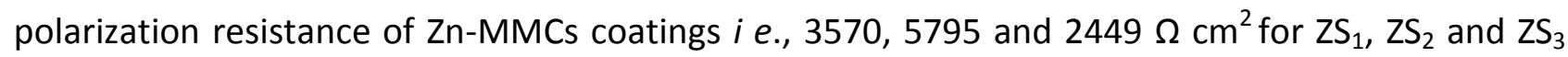
coatings respectively. It should be noted that, $\mathrm{SiC}$ incorporated zinc coatings exhibited more resistance for charge transfer with minimum double layer capacitance value when compared to pure zinc coating. The decrease in double layer capacitance value suggests that the electroactive behavior of the surface in corrosive environment is minimum and hence MMCs are much resistive towards external aggressive media. Among all, $\mathrm{ZS}_{2}$ deposit showed tenfold increase in $R_{\mathrm{ct}}$ value with decrease in $C_{\mathrm{dl}}$ value to the same extent.

The two capacitive loops which were observed in the Nyquist plot are also observed in Bode plots. The impedance modulus $|Z|$ vs. the frequency plot shows that impedance modulus value of the composite coatings are greater than that of $Z$ coating, and it is in accordance with the trend observed in polarization and Nyquist plot analysis.
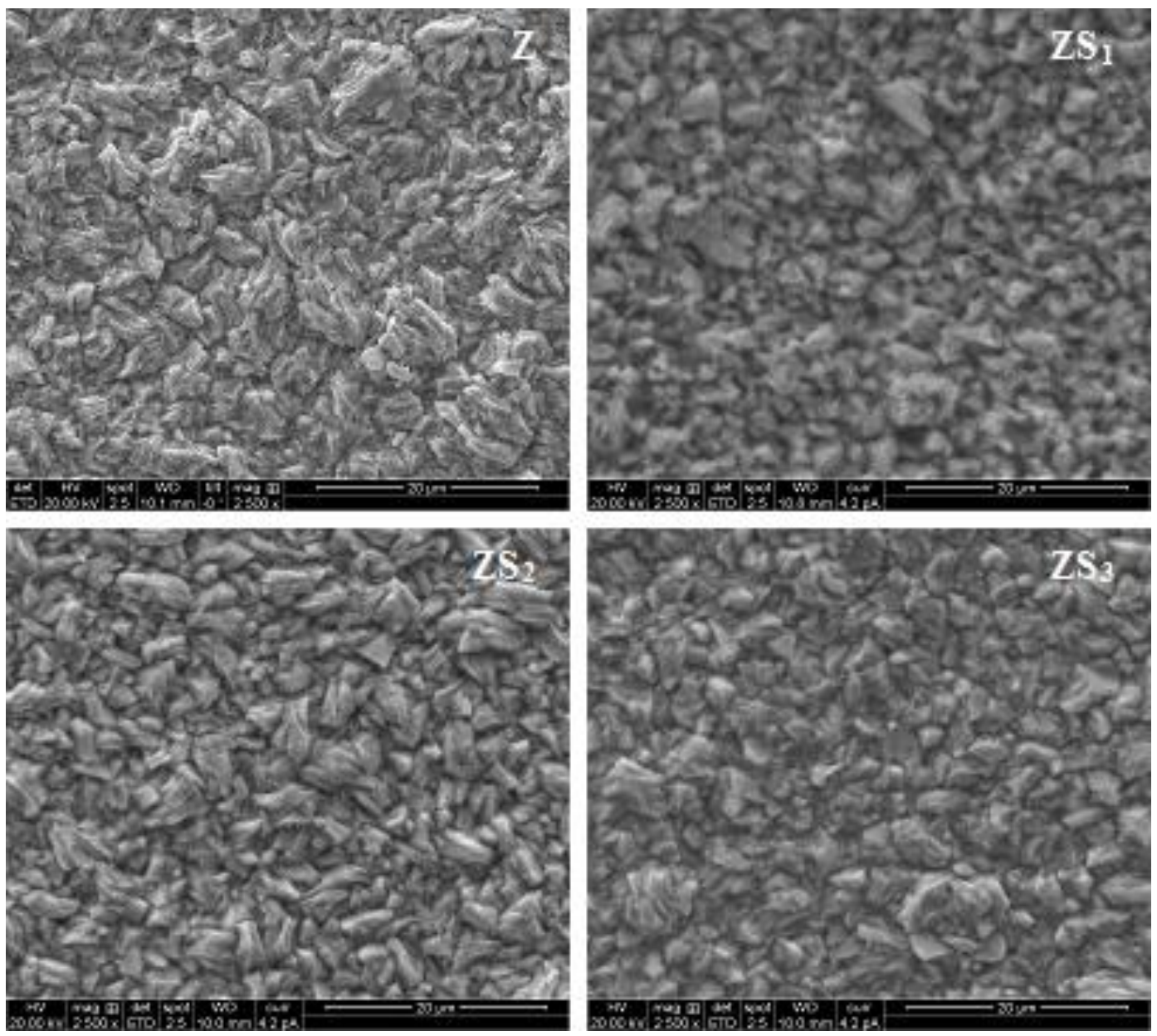

Figure 8. SEM micrographs of zinc and Zn-SiC composite coatings recorded after potentiodynamic polarization measurement. 
4. Electrochemical corrosion parameters obtained from EEC simulation of impedance Nyquist plots.

\begin{tabular}{ccccccc}
\hline Specimen & $C_{\text {coat }} / \mu \Omega^{-1} \mathrm{~cm}^{-2} \mathrm{~S}^{-\mathrm{n}}$ & $\mathrm{n}_{\text {coat }}$ & $R_{\text {coat }} / \Omega \mathrm{cm}^{2}$ & $R_{\mathrm{ct}} / \Omega \mathrm{cm}^{2}$ & $C_{\mathrm{dl}} / 10^{-3} \mathrm{~F} \mathrm{~cm}^{-2}$ & ${ }^{*} R_{\mathrm{p}} / \Omega \mathrm{cm}^{2}$ \\
\hline $\mathrm{Z}$ & 29.14 & 0.817 & 419.6 & 75.2 & 6.968 & 494.8 \\
$\mathrm{ZS}_{1}$ & 16.38 & 0.864 & 2530 & 1040 & 0.340 & 3570 \\
$\mathrm{ZS}_{2}$ & 13.31 & 0.931 & 4188 & 1607 & 0.451 & 5795 \\
$\mathrm{ZS}_{3}$ & 6.784 & 0.946 & 1768 & 681 & 0.692 & 2449 \\
\hline
\end{tabular}

${ }^{*} R_{\mathrm{p}}=R_{\text {coat }}+R_{\mathrm{ct}}$

Also the SEM images of the deposits after polarization (Figure 8) shows that the composite coating surface is less deteriorated and retained its compactness when compare to pure zinc coating. Furthermore, the uniform corrosion process was observed on all deposit surfaces and it confirms the defect free nature of the zinc coatings. If deposit has defects then the pitting corrosion behavior is expected.

It is already reported that, the inclusion of $\mathrm{SiC}$ nanoparticles to zinc matrix will improve the mechanical properties of the deposit [12]. However, the results gathered from the present work confirm that the incorporation of $\mathrm{SiC}$ nanoparticles also enhance the corrosion resistance property of the zinc coatings.

The dissolution of metallic coating depends on the texture, morphology and chemical composition of the deposit $[14,20]$. Under aggressive environment, the dissolution activities vary because of the difference in binding energy of atoms between the crystallographic planes. The deposits having the crystallographic planes with higher number of adjacent atoms requires higher energy to breakdown the atoms followed by their dissolution. Therefore more energy is required to breakdown the close packed planes or low-index planes because they are associated with high bonding energy of the surface atoms [20].

All the coatings in particular $\mathrm{ZS}_{2}$ exhibit maximum orientation in (100) and (101) planes. So all the coatings including pure zinc coating has to show high corrosion resistance. But better anticorrosion behavior was noticed for composite coatings in particular $\mathrm{ZS}_{2}$, Because Since the different texture and grain boundary distribution of the coating also influences on the corrosion behavior of the coatings. As a result, we observed different corrosion resistance property for zinc coatings.

\section{Micro-Hardness analysis}

The measured Vickers micro-hardness value for $\mathrm{Zn}$ and $\mathrm{Zn}$-SiC MMCs is given in Figure 9. The given micro-hardness values were an average of 5 measurements performed on different locations at the centre portion of coated samples.

The slightly increased micro-hardness value was observed for Zn-SiC MMCs compared to pure zinc coating, because of the minimum incorporation of SiC nanoparticles in metal matrix. Also, it can be observed that there is no significant difference in micro-hardness value between $\mathrm{ZS}_{1}, \mathrm{ZS}_{2}$ and $\mathrm{ZS}_{3}$ coating. It may be due to the percentage of $\mathrm{SiC}$ incorporation is comparatively equal in all the MMCs. However, MMCs exhibit better micro-hardness value compared to that of pure zinc coating. It can be supposed that nanoparticles co-deposited in the composite coating might act as barriers to impede the plastic deformation of $\mathrm{Zn}$ matrix and hence enhance the micro hardness [21]. 


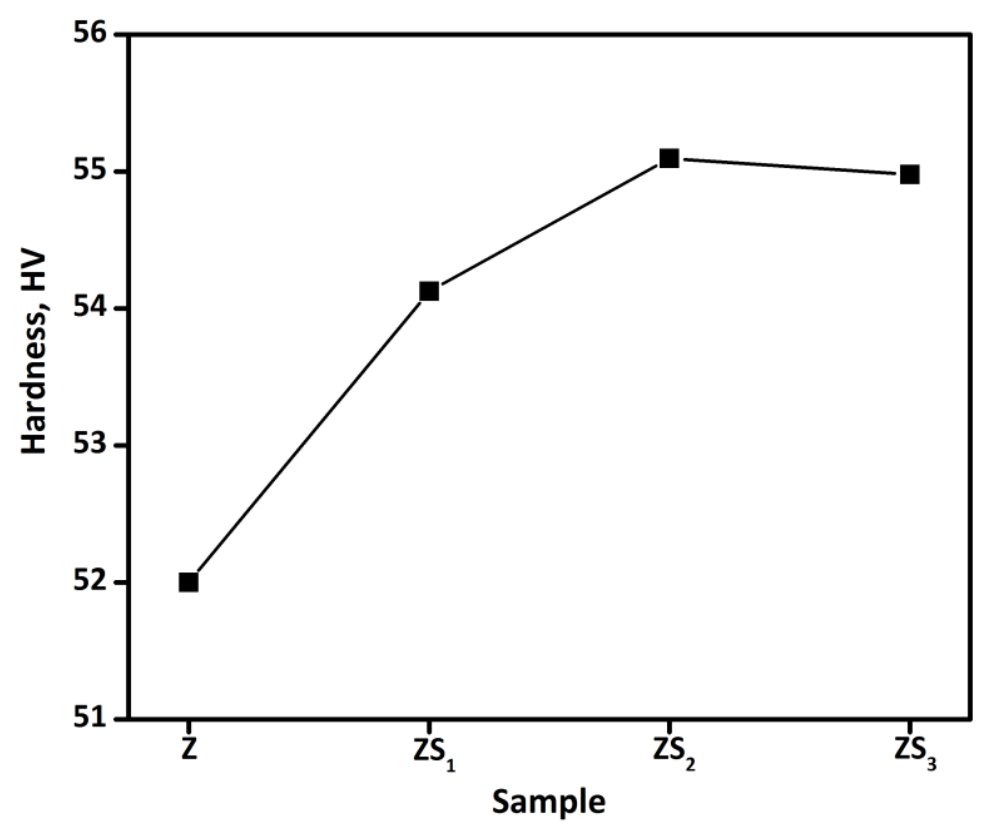

Figure 9.Vickers micro-hardness value of $\mathrm{Zn}$ and $\mathrm{Zn}$-SiC MMCs.

\section{Conclusions}

The $\mathrm{Zn}$-SiC composite coatings were successfully generated on mild steel by electrodeposition method. The SEM and XRD analysis demonstrate that, the incorporation of SiC nanoparticles considerably change the morphology and microstructure of the deposits. The preferred orientation of the zinc crystallites in SiC incorporated coatings is changed to (101) plane from (100) plane of the zinc crystallite in pure zinc coating. Also uniform and compact nature was observed in $\mathrm{Zn}$-SiC MMCs. The incorporation of SiC nanoparticles in to zinc metal matrix improved the microhardness property of the deposit. The electrochemical corrosion studies reveal that $\mathrm{Zn}-\mathrm{SiC}$ composite coatings have better corrosion resistance property than pure zinc coating. Compare to pure zinc coating, 60 to $80 \%$ decrease in corrosion rate was observed for composite coatings; in particular, $\mathrm{ZS}_{2}$ coating has significant resistance towards external aggressive media. The passive barrier behavior of uniformly distributed $\mathrm{SiC}$ nanoparticles and morphological changes may responsible for the anticorrosive behavior of the $\mathrm{Zn}$-SiC MMCs.

Acknowledgements: The authors thank Kuvempu University Karnataka, India for providing the laboratory facilities to bring about this work, and also the Department of Science and Technology (DST), New Delhi, Government of India (GOI) for providing financial support by Major Research Project [project no. S.R/S3/ME/014/2007].

\section{References}

[1] T- J. Tuaweri, G. D. Wilcox, Surf. Coat. Technol. 200 (2006) 5921-5930.

[2] C. M. Praveen kumar, T. V. Venkatesha, K. G. Chandrappa, Surf. Coat. Technol. 206 (2012) 2249-2257.

[3] C. B. Wang, D. L. Wang, W. X. Chen, Y. Y. Wang, Wear. 253 (2002) 563-571.

[4] A. Vlasa, S. Varavara, A. Pop, C. Bulea, L. M. Muresan, J. Appl. Electrochem. 40 (2010) 1519-1527.

[5] K. Vathsala, T. Venkatarangaiah Venkatesha, Appl. Surf. Sci. 257 (2011) 8929-8936.

[6] S. M. A. Shibli, F. Chacko, Surf. Coat. Technol. 202 (2008) 4971-4975.

[7] H. Chang, T. T. Tsung, L. C. Chen, C. S. Jwo, J. W. Tsung, Y. C. Lu, J. Mater. Eng. Perform, 14 (2005) 158-162. 
[8] F. Hu, K. C. Chan, S. Z. Song, X. J. Yang, J. Solid State Electrochem. 11 (2007) 745-750

[9] M. R. Vaezi, S. K. Sadrnezhaad, L. Nikzad, Colloid. Surface A: Physicochem. Eng. Aspects. 315 (2008) 176-182.

[10] S. K. Kim, H. J. Yoo, Surf. Coat. Technol. 108-109 (1998) 564-569.

[11] A. Swiderska-Sroda, J. A. Kozubowski, A. Maranda-Niedbala, E. Grzanka, B. F. Palosz, A. Presz, S. Gierlotka, S. Stelmakh, G. Kalisz, N. Herlin-Boime, C. Lathe, Solid State Phenomena. 101102 (2005) 151-156.

[12] G. Roventi, T. Bellezze, R. Fratesi, J. Appl. Electrochem. 43 (2013) 839-846.

[13] A. L. Patterson, Phys. Rev. 56 (1939) 978-82.

[14] K. O. Nayana, T. V. Venkatesha, B. M. Praveen, K. Vathsala, J. Appl. Electrochem. 41 (2011) 39-49.

[15] M. Mouanga, L. Ricq, J. Douglade, P.Berçot, Corros. Sci. 51 (2009) 690-698.

[16] F. La Mantia, J. Vetter, P. Nov'ak, Electrochim. Acta. 53 (2008) 4109-4121.

[17] J. Macak, P. Sajdl, P. Kucera, R. Novotny, J. Vosta, Electrochim. Acta. 51 (2006) 3566-77.

[18] A. K. Mishra, R. Balasubramaniam, S. Tiwari, Anti-Corros. Method. M. 54(1) (2007) 37-46.

[19] S. Ranganatha, T. V. Venkatesha, RSC Adv. 4 (2014) 31230-31238.

[20] H. Park, J. A. Szpunar, Corr. Sci. 40 (1998) 525-545.

[21] L. M. Chang, M. Z. An, H. F. Guo and S. Y. Shi, Appl. Surf. Sci. 253 (2006) 2132-2137.

(C) 2015 by the authors; licensee IAPC, Zagreb, Croatia. This article is an open-access article distributed under the terms and conditions of the Creative Commons Attribution license (http://creativecommons.org/licenses/by/4.0/) (cc) EY 